\title{
Understanding the Motivations of Female Entrepreneurs
}

\section{Tomas Chamorro-Premuzic ${ }^{1 *}$, Carlotta Rinaldi', Reece Akhtara ${ }^{1}$ and Gorkan Ahmetoglu ${ }^{2}$}

${ }^{1}$ Department of Psychology, UCL, London, UK 26 Bedford Way, London, WC1H OAP, UK

${ }^{2}$ Institute of Management Studies, Goldsmiths, University of London, London, UK New Cross, London, SE14 6NW, UK

\begin{abstract}
This paper investigates the psychological factors of female entrepreneurship, with a particular focus on personality and motivational factors - addressing a weakness in the existing literature. Through the use of two psychometric measures, the Measure of Entrepreneurial Tendencies and Abilities, and the Motives, Values and Preferences Inventory, female entrepreneurs are strongly motivated by a need for power, commerce, logical decision making, aesthetics and a need for change. Theoretical and practical implications are discussed.
\end{abstract}

Keywords: Women; Entrepreneurship; Personality; Motivators; Psychology

\section{Introduction}

In early 2000, the rate of new businesses created by women considerably outpaced the rate of new businesses created by men, with similar trends occurring in the rest of the developing world (Center for Women's Business Research) [1]. Furthermore, by 2012 companies founded by women accounted for over \$3 trillion of United States' GDP [2]. In light of this, female entrepreneurs are now considered key drivers of economic growth; however the underlying psychological processes remain under-researched. Although the relationship between entrepreneurship and gender-specific traits was first explored by McClelland [3], it was not further analysed till the late 1990s, when feminist theoretical and empirical studies [4-6] arose as an attempt to explain how female entrepreneurship was linked to variables such as the allocation of family resources, childbearing decisions, opportunity perceptions, self-confidence and poverty [7]. Nonetheless, the identity, belief and value systems of female entrepreneurs remain unknown, despite calls from researchers $[8,9]$. It is hypothesised that by understanding the motivational factors of female entrepreneurs, as a variable of their personality, gender-specific entrepreneurship interventions can be further developed. It is this research question that is the focus of this paper.

\section{Entrepreneurship}

While there is agreement on entrepreneurship's role as a stimulator of economic growth and job creation, academic research has struggled to accurately define what entrepreneurial activity [10-12]. Although selfemployment is often indicated as a central aspect of entrepreneurship $[13,14]$, some researchers believe that business creation is neither a necessary or sufficient aspect of entrepreneurship [15]. For example entrepreneurial activity or behaviour can also occur outside (e.g. college students forming social clubs) or within others' organisations (e.g. corporate entrepreneurship), and does not always involve profit making (e.g. social entrepreneurship) [16].

It is important to note that despite the variation in what constitutes as entrepreneurial activity, there is consensus surrounding the general themes of entrepreneurial behaviour. This includes the ability to both recognise and take advantage of opportunities [17], and create value [18] through innovation [19]. In light of these inclusive representations of entrepreneurial activity and behaviour, the present paper will define entrepreneurship as a function of an individual's personality, as characterised by behaviours that are related to the creation of value through the exploitation of opportunities in novel and innovative ways [20-22].

\section{Entrepreneurship and Personality}

Traditionally entrepreneurial activity was not viewed as being a product of an individual's behaviour [23-25], however more recently; an entrepreneur's personality traits have been demonstrated to be important in the prediction of entrepreneurial activity and success [26-29]. To clarify, personality traits are defined as typical behavioural tendencies that are invariant across situations and observed to be consistent over time [30].

A meta-analysis conducted by [28] suggests that entrepreneurial success could be positively predicted by an individual's tendency to act innovatively, have a preference for risky decisions, and be motivated by a need for achievement and autonomy - findings replicated by Ahmetoglu et al. [31]. As a result, Ahmetoglu and Chamorro-Premuzic developed META, a Measure of Entrepreneurial Tendencies and Abilities, a psychometric instrument that is able to assess individual differences in the ability to recognise and exploit opportunities, innovate and create change. This instrument is based on the principle that individuals are more or less entrepreneurial as a function of their personality, which is dependent on their engagement with the above four abilities. The measure has found to be related to emotional intelligence and core-self evaluations [16], callous-unemotional traits [32] and vocational preferences [31].

\section{Female Entrepreneurship}

Within the western world, there is a growing trend in females participating in entrepreneurial activity. For example, within the European Union $34.4 \%$ of entrepreneurs are now females and in the United States there are more than 6.2 million privately held, womenowned firms [33]. Worldwide, the Gender-GEDI Executive Report (2013), a diagnostic tool that identifies the conditions that foster female entrepreneurship, found that the USA ranked number one, followed by

*Corresponding author: Tomas Chamorro-Premuzic, Department of Psychology, University College London, 26 Bedford Way, London WC1, UK, Tel: +447941386220; E-mail: t.chamorro@ucl.ac.uk

Receved November 04, 2013; Accepted February 22, 2014; Published February 27, 2014

Citation: Chamorro-Premuzic T, Rinaldi C, Akhtara R, Ahmetoglu G (2014) Understanding the Motivations of Female Entrepreneurs. J Entrepren Organiz Manag 3: 111. doi: 10.4172/2169-026X.1000111

Copyright: (c) 2014 Chamorro-Premuzic T, et al. This is an open-access article distributed under the terms of the Creative Commons Attribution License, which permits unrestricted use, distribution, and reproduction in any medium, provided the original author and source are credited. 
Australia, Germany and France for the overall score of entrepreneurial environment (cultural support and opportunity perception), ecosystem (competition, quality of human resources \& technology sector) and entrepreneurial aspirations (high growth, process innovation, internationalization \& external financing).

Empirical research has largely demonstrated that a major component leading to independent employment choice is the level of education. Although some argue against it, $[34,35]$ most conclude that female business owners have a higher university degree than the overall population majority [36-38]. As noted by the Gender-GEDI Executive Report "higher education not only provides high-potential female entrepreneurs with the skills needed to grow their businesses, but also broadens their networks, another critical factor for high-potential female entrepreneurship success" (p.9; 2013). A second trend identified by the literature is centred on the need to balance personal life and work responsibilities [39,40], often arising after the first child is born [41]. It must be noted that only $39 \%$ of professional women in 2005 chose to return to work full time after taking time off for family reasons [37]. As a result, female entrepreneurs usually tend to possess fewer years of business experience than men [42,43] and often none at all [44]. Strict and bureaucratic corporate environments deeply contributed to push women towards an independent start-up, allowing both greater wealth and flexibility [45].

Barriers to success have been revealed by several theorists to often be non-economic factors such as culture and institutions [46]. In the first case, social norms influence the general support that a particular culture provides to women choosing an entrepreneurial route. The number of gendered institutions (i.e women's entrepreneur's networks) therefore depends on the general population's willingness to accept and sustain the phenomenon. Feelings of guilt and tensions deriving from the public view on the traditional role of women in society may prevent female entrepreneurship expansion [47]. In the second case, if institutions do not facilitate and allow basic business freedoms indispensible for starting, running and exiting a business, the ration of female entrepreneurs will certainly decrease (Gender-GEDI Executive Report, 2013).

Finally, not enough research has been compiled over female entrepreneurs' personality motivators and drivers. Having needs for independence, achievement, self-fulfilment, social status and power are continually ranked among the first motivators of female selfemployment $[18,48,49]$. In particular, the need to achieve, a common value of female entrepreneurs [50] is based on the motivation to do well and accomplish goals within certain standards, all related to the perception of control [51]. Furthermore, female Entrepreneur's risktaking behaviour has been object of controversial discussion in the academic world. Some researchers are convinced of the moderate aspect of this personality trait [52-54] while others explain how risk-tolerance depends on an individual's self-confidence and locus of control $[55,56]$. In simple words, female entrepreneurs might be perceived by external entities as high risk-takers given their strong self-confidence and assertiveness but not necessarily by themselves. Overall, the majority of papers conclude that female business owners are risk-averse $[13,57]$ and prefer employing less-risky growth strategies in order for their enterprises to develop at a more solid pace [58].

The aforementioned research appears to suggest that the motivations of female entrepreneurs are important, yet the literature is mixed and inconsistent, this is largely due to previous investigations failing to use an established framework of psychological motivations, overuse of post hoc hypothesis and low statistical rigour. The lack of research that specifically investigates the relationship between personality traits and female entrepreneurs has created a need for further clarification so that practical interventions can be developed to potentially increase the success of female entrepreneurs.

The current study addresses the aforementioned criticisms by investigating the relationship between two psychometric measures: the aforementioned measure of entrepreneurial personality, META, and the Motives, Values, Preferences Inventory (MVPI) [59], a measure of an individual's motivations, identity concepts and values. The MVPI is a contextualized measure, in that its items are concerned with an individual's motivations at work. It consists of ten sub-scales and is well validated [60-62]. The relationship between an individual's motivations and entrepreneurial personality will be explored to identify the motivators possessed by female entrepreneurs, specifically between META's facets and the MVPI's sub-scales. Although the research is exploratory, yet in light of the aforementioned research, a specific hypothesis will be tested

- H1: Among MVPI sub-scales, power, commerce and aesthetics will positively predict increased entrepreneurial behaviour (META).

It is hoped that this hypothesis will confirm the emerging themes in the literature, while allow the identification of new motivators behind female entrepreneurship.

\section{Method}

\section{Participants}

A total of 150 female entrepreneurs were recruited through a range of female entrepreneurship networks based, in order of highest contribution volume, in the UK, USA and Italy. With regards to participants' job title, approximately $28.6 \%$ indicated they were a director; $15.7 \%$ were consultants/coaches, $15 \%$ were CEOs, $7 \%$ were owners, $5.7 \%$ were founders/co-founders, $5 \%$ were managers and only $2.8 \%$ indicated they were entrepreneurs.

\section{Measures}

Measure of Entrepreneurial Tendencies and Abilities (META); [31] META is a 61-item self-report scale measuring personality traits relevant in entrepreneurial success and consists of four dimensions: creativity ("I am always trying to find new ways of doing things"), opportunism ("I see business opportunities where others don't"), proactivity ("I like to get things started and make things happen") and vision ("My goal in life is to create something that transforms people's lives"). Participants respond to each item by a five point Likert scale, ranging from 'Strongly Disagree' (1) to 'Strongly agree' (5). A Principal Axis Factoring with an oblimin rotation revealed four factors, EA (11 items), EC (12 items), EO (18 items), and EV (20 items), which is in line with previous research [16]. See Table 1 for a measure of META's internal consistency [59].

\section{Motives, values, preferences inventory}

The MVPI describes the core goals, values, drivers and interests that determine what people desire and strive to attain. Values are measured along 10 primary scales, such as aesthetics ("I like to be around artists and writers"), affiliation ("I am a people person"), altruism "I like to spend my spare time helping others"), commerce ("I enjoy meeting people who are successful in business"), hedonism ("My idea of living is good food, good drink, and fun times), power ("I enjoy being in charge"), recognition ("I am annoyed when people don't treat me with the respect I deserve"), science ("I believe progress is only possible 


\begin{tabular}{|c|c|c|c|c|c|c|c|c|c|c|c|c|c|c|c|c|c|}
\hline & 1 & 2 & 3 & 4 & 5 & 6 & 7 & 8 & 9 & 10 & 11 & 12 & 13 & 14 & M & SD & $\alpha$ \\
\hline 1. META Total & - & & & & & & & & & & & & & & 149.82 & 16.21 & .86 \\
\hline 2. E Opportunism & $.88^{* *}$ & - & & & & & & & & & & & & & 34.35 & 5.99 & .73 \\
\hline 3. E Proactivity & $.81^{* *}$ & $.71^{* *}$ & - & & & & & & & & & & & & 37.36 & 5.15 & .71 \\
\hline 4. E Creativity & $.75^{* *}$ & $.53^{* *}$ & $.46^{* *}$ & - & & & & & & & & & & & 38.56 & 5.45 & .72 \\
\hline 5. E Vision & $.60^{* *}$ & $.38^{* *}$ & $.29^{* *}$ & $.27^{* *}$ & - & & & & & & & & & & 39.55 & 4.49 & .72 \\
\hline 6. Aesthetics & $.26^{* *}$ & $.20^{*}$ & .11 & $.36^{* *}$ & .11 & - & & & & & & & & & 3.37 & .95 & .71 \\
\hline 7. Affiliation & .12 & .12 & .16 & .06 & .00 & .11 & - & & & & & & & & 3.89 & .64 & .69 \\
\hline 8. Altruism & .00 & -.04 & .01 & .12 & -.09 & .07 & $.21^{*}$ & - & & & & & & & 3.44 & .73 & .73 \\
\hline 9. Commerce & $.37^{* *}$ & $.39^{* *}$ & $.27^{* *}$ & $.20^{*}$ & $.25^{* *}$ & .03 & .09 & .05 & - & & & & & & 3.95 & .58 & .69 \\
\hline 10. Hedonism & -.05 & -.02 & -.03 & -.12 & .02 & .08 & .15 & $-.21^{\star *}$ & .01 & - & & & & & 3.47 & .76 & .72 \\
\hline 11. Power & $.46^{* *}$ & $.27^{* *}$ & $.31^{* *}$ & $.33^{*+}$ & $.54^{* *}$ & .00 & .06 & .01 & $.29^{* *}$ & -.03 & - & & & & 4.22 & .58 & .73 \\
\hline 12. Recognition & .10 & .04 & -.07 & .05 & $.34^{* *}$ & $.17^{*}$ & .02 & .00 & .14 & .02 & $.23^{* *}$ & - & & & 3.47 & .78 & .69 \\
\hline 13. Science & $.23^{* *}$ & $.19^{*}$ & $.17^{*}$ & $.26^{* \star}$ & .08 & $.16^{*}$ & $-.20^{*}$ & .04 & -.05 & -.12 & .01 & .01 & - & & 2.80 & .87 & .74 \\
\hline 14. Security & $-.40^{* *}$ & $-.37^{* *}$ & $-.34^{* *}$ & $-.47^{* *}$ & .00 & -.11 & -.13 & -.14 & -.08 & $.17^{*}$ & -.15 & .11 & -.09 & - & 2.39 & .74 & .72 \\
\hline 15. Tradition & $-.24^{* *}$ & $-.18^{*}$ & $-.26^{* *}$ & $-.24^{* *}$ & -.03 & $-.20^{*}$ & -.03 & $.22^{* *}$ & -.03 & .02 & .01 & .13 & .07 & $.35^{* *}$ & 3.98 & .69 & .69 \\
\hline
\end{tabular}

Note: $2-5=$ META facets, $6-15=$ MVPI sub-scales. $E=$ Entrepreneurial. ${ }^{*} p<.050$ (two-tailed), ${ }^{* *} p<.010$ (two-tailed).

Table 1: Descriptive statistics, bivariate correlations and alpha coefficients for META and MVPI.

\begin{tabular}{|c|c|c|c|c|c|c|c|c|c|c|}
\hline & \multicolumn{2}{|c|}{ META Total } & \multicolumn{2}{|c|}{ Opportunism } & \multicolumn{2}{|c|}{ Proactivity } & \multicolumn{2}{|c|}{ Creativity } & \multicolumn{2}{|c|}{ Vision } \\
\hline & $\beta$ & $\mathrm{t}$ & $\beta$ & $\mathrm{t}$ & $\beta$ & $\mathrm{t}$ & $\beta$ & $\mathrm{t}$ & $\beta$ & $\mathrm{t}$ \\
\hline Aesthetics & .17 & $2.62^{* *}$ & .12 & 1.65 & \multicolumn{2}{|c|}{-} & .28 & $4.21^{* \star *}$ & \multicolumn{2}{|c|}{-} \\
\hline Commerce & .25 & $3.86^{* * *}$ & .33 & $4.66^{\star * *}$ & .19 & $2.56^{* *}$ & .10 & 1.51 & .09 & 1.20 \\
\hline Power & .35 & $5.40^{* * *}$ & .13 & 1.86 & .22 & $2.94^{\star * *}$ & .24 & $3.66^{\star * *}$ & .46 & $6.44^{* * *}$ \\
\hline Recognition & \multicolumn{2}{|c|}{-} & \multicolumn{2}{|c|}{-} & \multicolumn{2}{|c|}{-} & \multicolumn{2}{|c|}{-} & .22 & $3.15^{\star *}$ \\
\hline Science & .20 & $3.24^{* *}$ & .17 & $2.40^{\star *}$ & .17 & $2.37^{*}$ & .19 & $2.94^{* *}$ & \multicolumn{2}{|c|}{-} \\
\hline Security & -.25 & $-3.77^{\star \star *}$ & -.28 & $-3.70^{* \star *}$ & -.21 & $-2.70^{\star *}$ & -.35 & $-5.09^{\star \star *}$ & \multicolumn{2}{|c|}{-} \\
\hline Tradition & -.13 & $-1.92^{*}$ & -.07 & -.89 & -.20 & $-2.58^{* *}$ & -.07 & -1.02 & \multicolumn{2}{|c|}{-} \\
\hline$F(6,143)=$ & \multicolumn{2}{|c|}{$21.24^{\star * *}$} & \multicolumn{2}{|c|}{$12.08^{* * *}$} & \multicolumn{2}{|c|}{$10.74^{* * *}$} & \multicolumn{2}{|c|}{$18.02^{* \star *}$} & \multicolumn{2}{|c|}{$25.25^{* * *}$} \\
\hline $\operatorname{Adj~} R^{2}=$ & \multicolumn{2}{|c|}{.45} & \multicolumn{2}{|c|}{.31} & \multicolumn{2}{|c|}{.25} & \multicolumn{2}{|c|}{.41} & \multicolumn{2}{|c|}{.33} \\
\hline
\end{tabular}

${ }^{*} \mathrm{p}<.050$ (two-tailed)

${ }^{* *} p<.010$ (two-tailed)

$\star * * p<.001$ (two-tailed)

Table 2: Results of a series of linear regressions that predicted META scores from MVPI factors.

through scientific research"), security (I don't like unpredictable situations"), tradition ("I am pretty strict about right and wrong"). Each of the 10 factors was tested with three questions on a five-point Likert scale, ranging from strongly disagree to strongly agree. Table 1 for a measure of the MVPI's internal consistency.

\section{Procedure}

Participants were recruited through professional networks, social media sites (such as LinkedIn, Facebook and Twitter), emails and posts in relevant forums. Participants provided biographical information, followed by the META and MVPI questionnaires. Feedback across both measures was given upon completion.

\section{Results}

Before any analyses were carried out, the data was cleaned for any missing values and anomalies, while ensuring the assumptions of the general linear model were not violated [63]. Descriptive statistics and bivariate correlations for both measures are presented in Table 1. As demonstrated, the mean for the total META scores is 149.82 out of 200 $(\mathrm{SD}=16.21)$, suggesting a high prevalence of entrepreneurial tendencies within the current sample, while demonstrating META's internal consistency through acceptable alpha levels both within the entire scale and between its facets, and through the significant inter-correlations held between each of the four facets.

By exploring the correlations between the MVPI's sub-scales and META, power was most strongly associated with META, followed by commerce, aesthetics and science. Conversely, negative relationships can be observed between security and META, as well as between tradition and META.

\section{Multiple regressions}

To further explore the relationship between META and MVPI, alongside testing test this paper's hypothesis, a series of multiple regressions were carried out. In total five models were tested, with META facets and it's a total score acting as dependent variables, with the MVPI sub-scales acting as predictors. By specifying each of META's facets as a dependent variable, it was hoped that a more nuanced insight could have been achieved as specific relationships could be explored. MVPI sub-scales were included in the regressions only if they were significantly correlated with a META facet or its total score. Table 2 
displays the results of these analyses, and subsequently supports this paper's hypothesis.

The first regression model featured total META scores as a dependent variable. With aesthetics, commerce, power, recognition, science, security and tradition acting as predictors, $45 \%$ of the variance in META scores was significantly accounted for. A need for commerce and power strongly predicted increased META scores, while a need for security and tradition negatively predicted lowered META scores. Similar findings were found in models whereby entrepreneurial opportunism and entrepreneurial proactivity were dependent variables, with $31 \%$ and $25 \%$ of the variance accounted for respectively. When predicting entrepreneurial creativity, $41 \%$ of the variance was accounted for. While a need for aesthetics most positively predicted scores, a need for security most negatively predicted scores. Finally, when predicting entrepreneurial vision, the needs for power and recognition were the only significant predictors, accounting for $33 \%$ of the variance. Unlike previous regression models, the need for recognition was the only MVPI significantly associated with a META facet. The theoretical implications of these results will be discussed.

\section{Discussion}

The main purpose of this study was to explore the psychological motivations behind the rising trend of female entrepreneurship, using a novel conceptualization of entrepreneurial behavior (META), and an established framework of psychological motivations and identity concepts (MVPI). As hypothesized, a need for power, commerce and aesthetics (in order of strongest correlations) were found to positively predict entrepreneurship behavior, as represented by total META scores. Although not hypothesized, a need for science, security and tradition were also found to predict entrepreneurial behavior, except for the latter two motivations predicting lower META scores. This is unsurprising, given the notion that entrepreneurs are innovators and are comfortable with risk [64]. These findings provide support for the female entrepreneurs being motivated by a need for achievement, independence and social status $[18,50]$, while challenging the literature that suggests female entrepreneurs are more risk-averse, than male counterparts $[13,57]$.

Unlike existing literature, this study identified the importance of aesthetic motivations: personal values and lifestyle choices that are focused on creative expression, imagination, culture, and attractive surroundings [65]). This finding suggests that female entrepreneurs therefore are characterized by a sense of qualitative innovation, and caring about product standards.

Although not hypothesized, a need for Science (valuing curiosity, analytics, problem solving and using new technologies; Hogan [65]) was found to positively predict total META scores alongside all META facets except entrepreneurial creativity. When interpreting this finding alongside, other positive predictors (power, commerce and aesthetics), it is not unsurprising. In fact, a businesswomen's desire to accomplish an economic success, while creatively self-express themselves, is accompanied by an accurate disciplined evaluation of possible decisions. A value for evidence therefore could be suggested as a way to regulate risky decisions, encourage logical reasoning and balance novelty with pragmatism. When combined with a low need for security and tradition, multiple novel ideas can be entertained without feeling fearful, while challenging the norm [66].

To summarize, the data suggests that female entrepreneurs are driven by an inner desire to control and influence their environment (power), to financially succeed (commerce) and to creatively self- express themselves in all aspects (aesthetics). Given their curious and analytical personality (science), they enjoy taking intuitive risks (low security) in order to challenge the status quo and dynamically contribute to the progress of society (low tradition).

\section{Limitations and Future Research}

The current study of course has some limitations that must be considered. First of all, the sample was selected only from western countries, therefore restricting the findings to a very specific area of the world and making it partly irrelevant to understand the wider phenomenon of female entrepreneurship. Moreover, the use of an abbreviated version of the MVPI (only three items per scale, rather than 20) may have affected its robustness as a valid psychometric measure. Lastly, and most importantly, the data collected is only self-report. Objective and subjective measures of entrepreneurial success such as those featured in Akhtar et al. [32] and Ahmetoglu et al. [16] would extend the current study's findings.

Future studies should implement the above into account, and may also consider including two other contextualized measures of personality, both of which belong to the same psychometric suite as the MVPI - the Hogan Personality Inventory (HPI) [67] and the Hogan Development Survey (HDS) [68]. While these two measures have not yet been used to explore entrepreneurial behaviour, the HPI, HDS and MVPI are built upon Socioanaltyic Theory [69]. By using each of the aforementioned, entrepreneurial behaviour can be holistically explained within a theoretical framework.

\section{Implications}

The results of this study has both applied and scientific significance. For what concerns the first case, policy makers and governmental bodies will be the first entity to benefit from learning about the motives of prospective female entrepreneurs. Training programs can be improved so that they are tailored to female entrepreneurs and ensure that the appropriate advice gets delivered [50]. Secondly, financial investors will better evaluate the entrepreneurial potential of specific individuals and select their funds' directions more successfully. This will certainly increase capital directed towards small business ideas, hopefully increasing innovation and economic growth. Regarding the latter, the research supports the notion that entrepreneurship is a function of an individual's personality and is not just confined to self-employment/ job creation. Additionally, the study further validates META as a measure of entrepreneurial behaviour, thereby demonstrating its use for the identification and selection of individuals who may possess entrepreneurial potential.

\section{References}

1. Center for Women's Business Research (2004) Women Owned Businesses in 2004: Trends in the U.S. and 50 States. Center for Women's Business Research, Washington D.C, USA.

2. Chamorro-Premuzic T (2012) How Bad Leadership Spurs Entrepreneurship.

3. McClelland DC (1961) The achieving society. Free Press, London, UK.

4. Blau FD (1998) Trends in the well-being of American women, 1970-1995 Journal of Economic Literature 36: 112-165.

5. Hurley A (1999) Incorporating feminist theories into sociological theories of entrepreneurship. Women in Management Review 14: 54-62.

6. Snyder MG (1995) Feminist theory and planning theory: Lessons from feminist epistemologies. Berkley Planning Journal 10: 91-106.

7. Minniti M, Naudé W (2010) What Do We Know About The Patterns and Determinants of Female Entrepreneurship Across Countries. European Journal of Development Research 22: 277-293. 
8. De Bruin A, Brush CG, Welter F (2006) Introduction to the special Issue: Towards building cumulative knowledge on women's entrepreneurship. Entrepreneurship Theory and Practice 30: 585-593.

9. Greene PG, Brush CG, Gatewood E (2007) Perspectives on women entrepreneurs: Past findings and new directions. Praeger Publisher Greenwood Publishing Group.

10. Brush CG (2006) Growth-oriented women entrepreneurs and their businesses: A global research perspective. Edward Elgar Publishing, Camberley, UK

11. Hisrich RD (1990) Entrepreneurship/intrapreneurship. American Psychologis 45: 209-222.

12. Orhan M, Scott D (2001) Why women enter into entrepreneurship: an explanatory model. Women in Management Review 16: 232-247.

13. Parker SC (2009) The Economics of Entrepreneurship. Cambridge University Press, Cambridge, UK.

14. Praag M (1999) Some Classic Views of Entrepreneurship. The Economist 147 311-335.

15. McKenzie B, Ugbah SD, Smothers N (2007) Who is Entrepreneur? Is it still the wrong question? Academy of Entrepreneurship Journal 13: 23-43.

16. Ahmetoglu G, Leutner F, Chamorro-Premuzic T (2011) EQ-nomics: Understanding the relationship between individual differences in trait emotional intelligence and entrepreneurship. Personality and Individual Differences 51: 1028-1033.

17. Bygrave W (1994) The entrepreneurial process. The Portable MBA in Entrepreneurship, Wiley, New York, USA.

18. Sarri K, Trihopoulou A (2005) Female entrepreneurs' personal characteristics and motivation: a review of the Greek situation. Women in Management Review 20: 24-36.

19. Stevenson HH, Gumpert DE (1991) The heart of entrepreneurship. The Entrepreneurial Venture, Harvard Business School Press, Boston, MA

20. Hisrich RD, Peters MP, Shepherd DA (2005) Entrepreneurship, 6th edition McGraw-Hill/Irwin, New York, USA.

21. Kuratko DF (2007) Entrepreneurial leadership in the 21stcentury: Guest editor's perspective. Journal of Leadership and Organizational Studies 13: 1-11.

22. McKenzie B, Ugbah SD, Smothers N (2007) Who is Entrepreneur? Is it still the wrong question? Academy of Entrepreneurship Journal 13: 23-43.

23. Brockhaus RH, Horwitz PS (1985) The psychology of the entrepreneur DL Sexton \& RW Smilor Editions, The art and science of entrepreneurship, Cambridge, Ballinger, USA.

24. Gartner WB (1989) "Who is an entrepreneur?" is the wrong question. Entrepreneurship Theory and Practice 12: 47-68.

25. Low MB, MacMillan BC (1988) Entrepreneurship: Past research and future challenges. Journal of Management 14: 139-162.

26. Chell E, Haworth JM, Brearley S (1991) The entrepreneurial personality, Routledge, London.

27. Rauch A, Frese M (2000) Psychological approaches to entrepreneuria success: A general model and an overview of findings. John Wiley \& Sons Ltd, New York, USA.

28. Rauch A, Frese M (2007) Let's put the person back into entrepreneurship research: A meta-analysis on the relationship between business owners' personality traits, business creation, and success. European Journal of Work and Organizational Psychology 16: 353-385.

29. Zhao H, Seibert SE (2006) The Big Five personality dimensions and entrepreneurial status: A meta-analytical review. Journal of Applied Psychology 91: 259-271.

30. Roccas S, Sagiv L, Schwartz SH, Knafo A (2002) The big five personality factors and personal values. Personality and Social Psychological Bulletin 28 : 789-801.

31. Ahmetoglu G, Chamorro-Premuzic T (2010) Measure of entrepreneurial tendencies and abilities. Unpublished Measure (available on request).

32. Akhtar R, Ahmetoglu G, Chamorro-Premuzic T (2013) Greed is good? Assessing the relationship between entrepreneurship and subclinical psychopathy. Personality and Individual Differences 54: 420-425.
33. Wilson F, Marlino D, Kickul J (2004) Our entrepreneurial future: Examining the diverse attitudes and motivations of teens across gender and ethnic identity. Journal of Developmental Entrepreneurship 9: 177-197.

34. Birley S, Moss C, Saunders P (1987) Do women entrepreneurs require different training. American Journal of Small Business 12: 27-35.

35. Naranjo-Valencia JC, Jiménez-Jiménez D, Sanz-Valle R (2011) Innovation or imitation? The role of organizational culture. Management Decision 49: 55-72.

36. Cowling M, Taylor MP (2001) Entrepreneurial women and men: Two differen species? Small Business Economics 16: 167-175.

37. Sandberg S (2013) Lean in: Women, work and the will to lead. Random House.

38. Stefanović S, Stošić D (2012) Specifics and challenges of female entrepreneurship. Economic Themes 50: 327-343.

39. Marlow S, Strange A (1994) Female entrepreneurs: success by whose standards? International Journal of Gender and Entrepreneurship 3: 88-104.

40. Mattis MC (2004) Women entrepreneurs: Out from under the glass ceiling Women in Management Review 19: 154-163.

41. Anderson AR, Dodd SD, Jack SL (2012) Entrepreneurship as connecting: some implications for theorising and practice. Management Decision 50: 958-971.

42. Audretsch D (2012) Entrepreneurship research. Management Decision 50 755-764.

43. Lee MA, Rendall MS (2001) Self-employment disadvantage in the working lives of blacks and females. Population Research and Policy Review 20: 291-320.

44. Watkins J, Watkins D (1983) The female entrepreneur: Background and determinants of business choice- Some British data. International Smal Business Journal 2: 21.

45. Walker EA, Webster BJ (2007) Gender, age and self-employment: Some things change, some stay the same. Women in Management Review 22: 122-135.

46. Elam A, Terjesen S (2010) Gendered institutions and cross-national patterns of business creation for men and women. European Journal of Development Research 22: 331-348

47. McGowan P, Redeker CL, Cooper SY, Greenan K (2012) Female entrepreneurship and the management of business and domestic roles: Motivations, expectations and realities. Entrepreneurship \& Regional Development 24: 53-72.

48. Glancey K, Greig M, Pettigrew M (1998) "Entrepreneurial dynamics in the smal business service sector". International Journal of Entrepreneurial Behavior \& Research 4: 249-268.

49. Orhan M, Scott D (2001) Why women enter into entrepreneurship: an explanatory model. Women in Management Review 16: 232-247.

50. Sirec K, Mocnik D (2012) Gender specifics in entrepreneurs' persona characteristics. Journal for East European Management Studies 17: 11-39.

51. Miller D, Friesen PH (1982) Innovation in conservative and entrepreneuria firms: Two models of strategic momentum. Strategic Management Journal 3 1-25.

52. Birley S, Norburn D (1987) Owners and managers: The venture 100 versus the Fortune 500. Journal of Business Venturing 2: 351-363.

53. Duchesneau DA, Gartner WB (1990) A profile of new venture success and failure in an emerging industry. Journal of Business Venturing 5: 297-312.

54. Shaver KG (1995) The entrepreneurial personality myth. Business and Economic Review 41: 20-23.

55. Kets de Vries MFR (1977) The entrepreneurial personality at the crossroads Journal of Management Studies 14: 34-57.

56. Rotter JB (1966) Generalized experiences for internal versus external control of reinforcement. Psychological Monographs 80: 1-28.

57. Watson J (2002) Comparing the Performance of Male and Female Controlled Businesses: Relating Outputs with Inputs. Entrepreneurship Theory \& Practice 26: $91-100$.

58. Cliff J (1998) Does one size fit all? Exploring the relationship between attitudes towards growth, gender and business size. Journal of Business Venturing 13 : 523-542.

59. Hogan J, Hogan R (1996) Motives, Values, Preferences Inventory Manual Hogan Assessment Systems, University of Tulsa, OK, USA. 
Citation: Chamorro-Premuzic T, Rinaldi C, Akhtara R, Ahmetoglu G (2014) Understanding the Motivations of Female Entrepreneurs. J Entrepren Organiz Manag 3: 111. doi: 10.4172/2169-026X.1000111

60. Furnham A, Hyde G, Trickey G (2013) The values of work success. Personality and Individual Differences 55: 485-489.

61. Giberson TR, Resick CJ, Dickson MW (2005) Embedding leader characteristics: An examination of homogeneity of personality and values in organizations. Journal of Applied Psychology 90: 1002-1010.

62. Warwick J, Nettelbeck T (2004) Emotional intelligence is...? Personality and Individual Differences 37: 1091-1100.

63. Judd CM, McClelland GH, Ryan CS (2009) Data Analysis: A Model Comparison Approach, Second edition, Routledge, New York, USA.

64. Schumpeter JA (2000) Entrepreneurship as innovation. Entrepreneurship: The social science view 51-75.
65. Hogan R, Hogan J, Warrenfeltz R (2007) The Hogan Guide: interpretation and use of Hogan inventories. Hogan Assessment Systems.

66. Collins CJ, Hanges PJ, Locke EE (2004) The relationship of achievement motivation to entrepreneurial behavior: A meta-analysis. Human Performance 17: 95-117.

67. Hogan J, Hogan R (1995) Hogan Personality Inventory Manual. Hogan Assessment Systems, University of Tulsa, OK, USA.

68. Hogan J, Hogan R (1997) Hogan Development Survey Manual. Hogan Assessment Systems, University of Tulsa, OK, USA.

69. Hogan R, Shelton D (1998) A Socioanalytic perspective on job performance. Human Performance 11: 129-144. 